\title{
Effects of Climate Change on Water Availability
}

\author{
Prof. Minghua Zhang
}

Director

Institute for Terrestrial and Planetary Atmospheres

School of Marine and Atmospheric Sciences

Stony Brook University

http://atmsci.msrc. sunysb.edu 


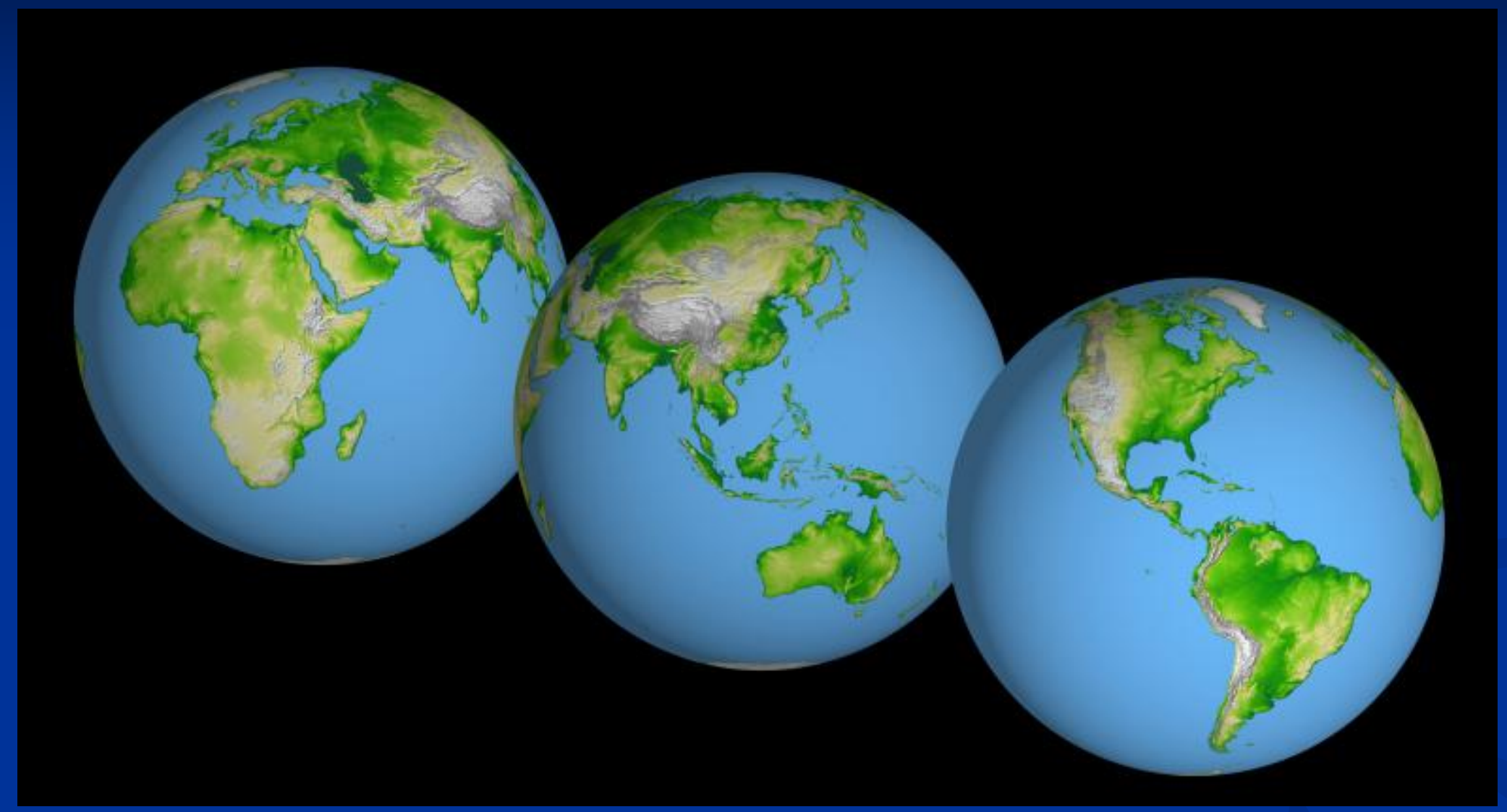

NASA 

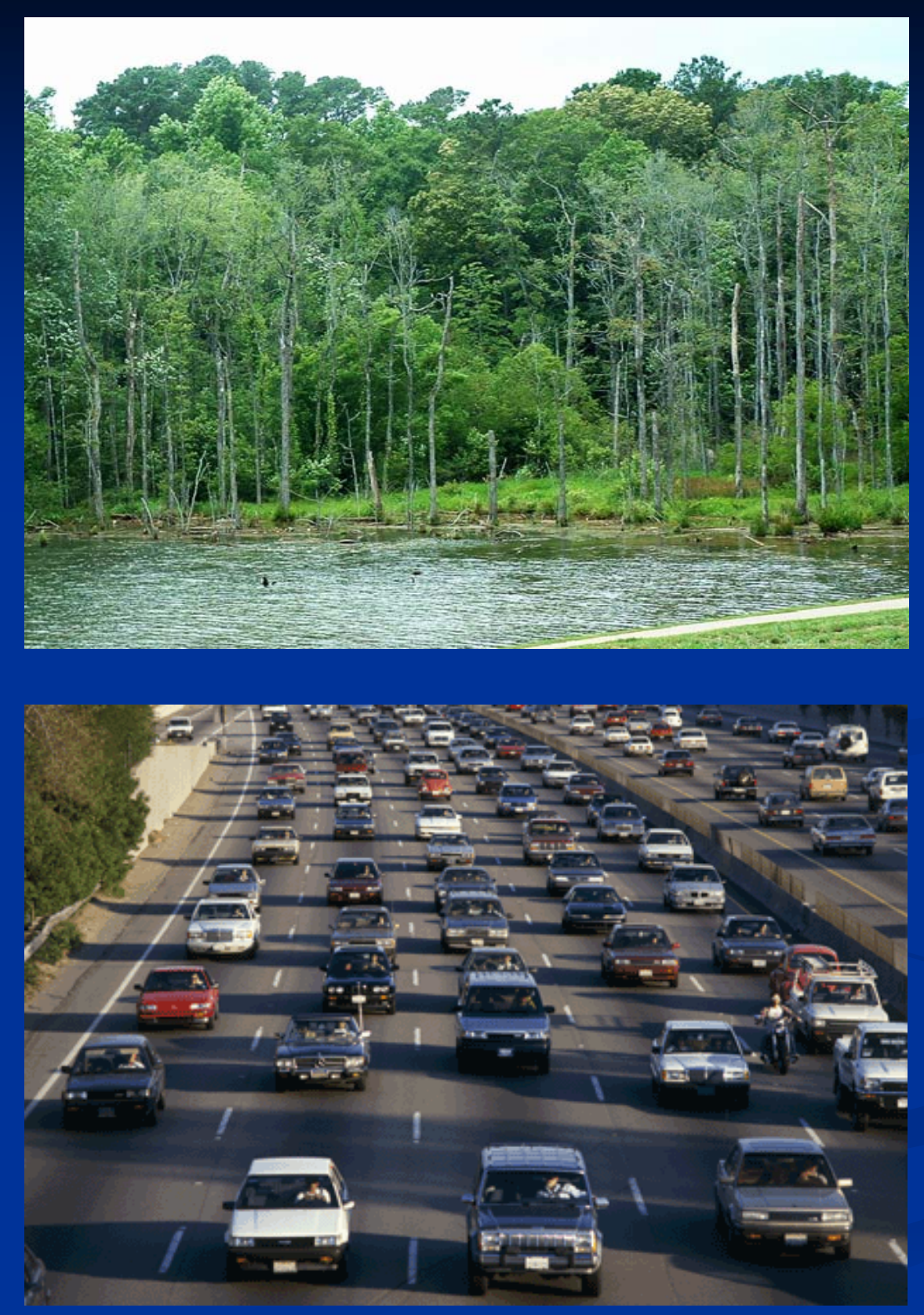
Annual $\mathrm{CO}_{2}$ Emission from fossil fuel burning and cement production

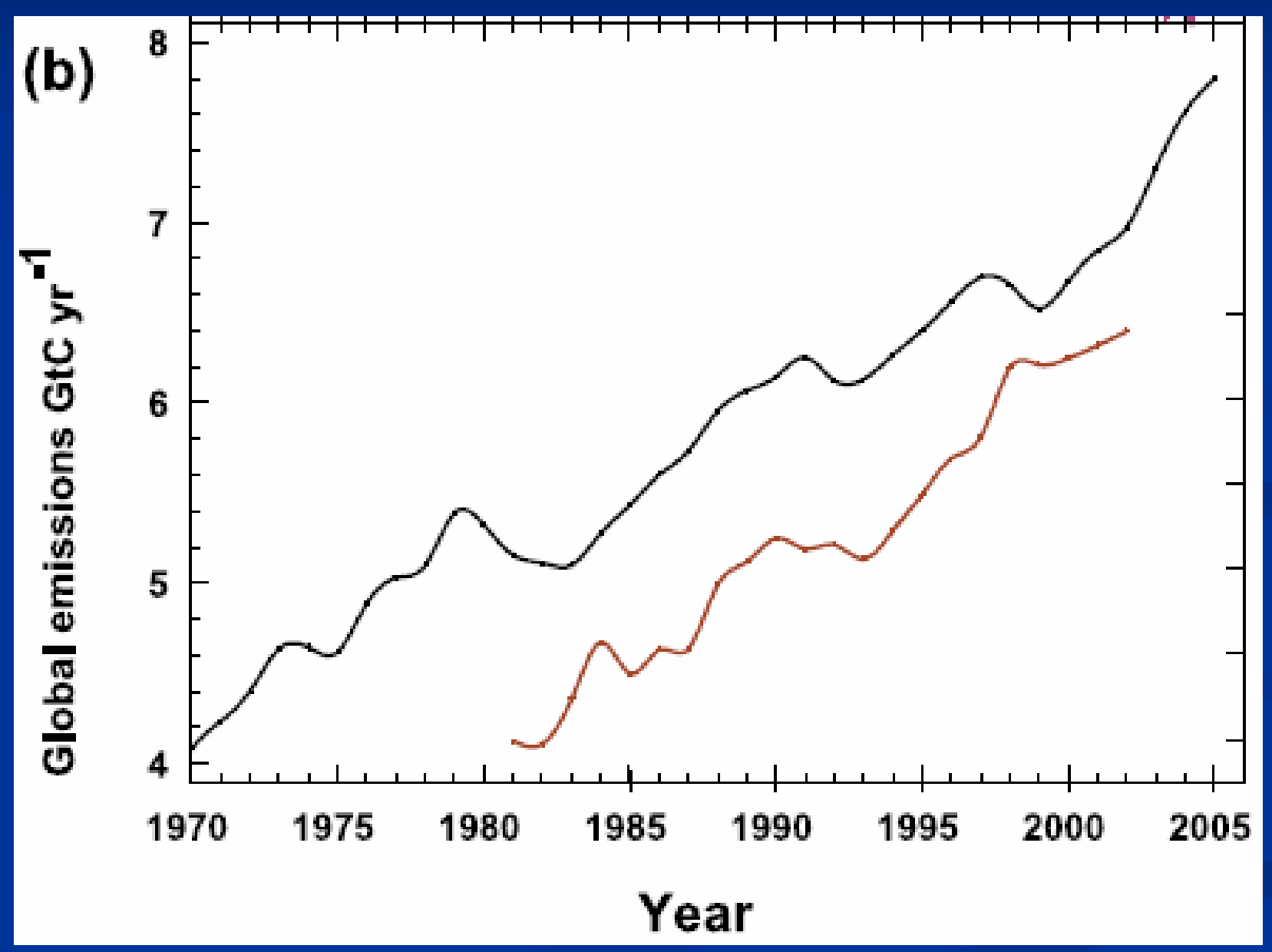


MAUNA LOA OBSERVATORY, HAWAII

MONTHLY AVERAGE CARBON DIOXIDE CONCENTRATION

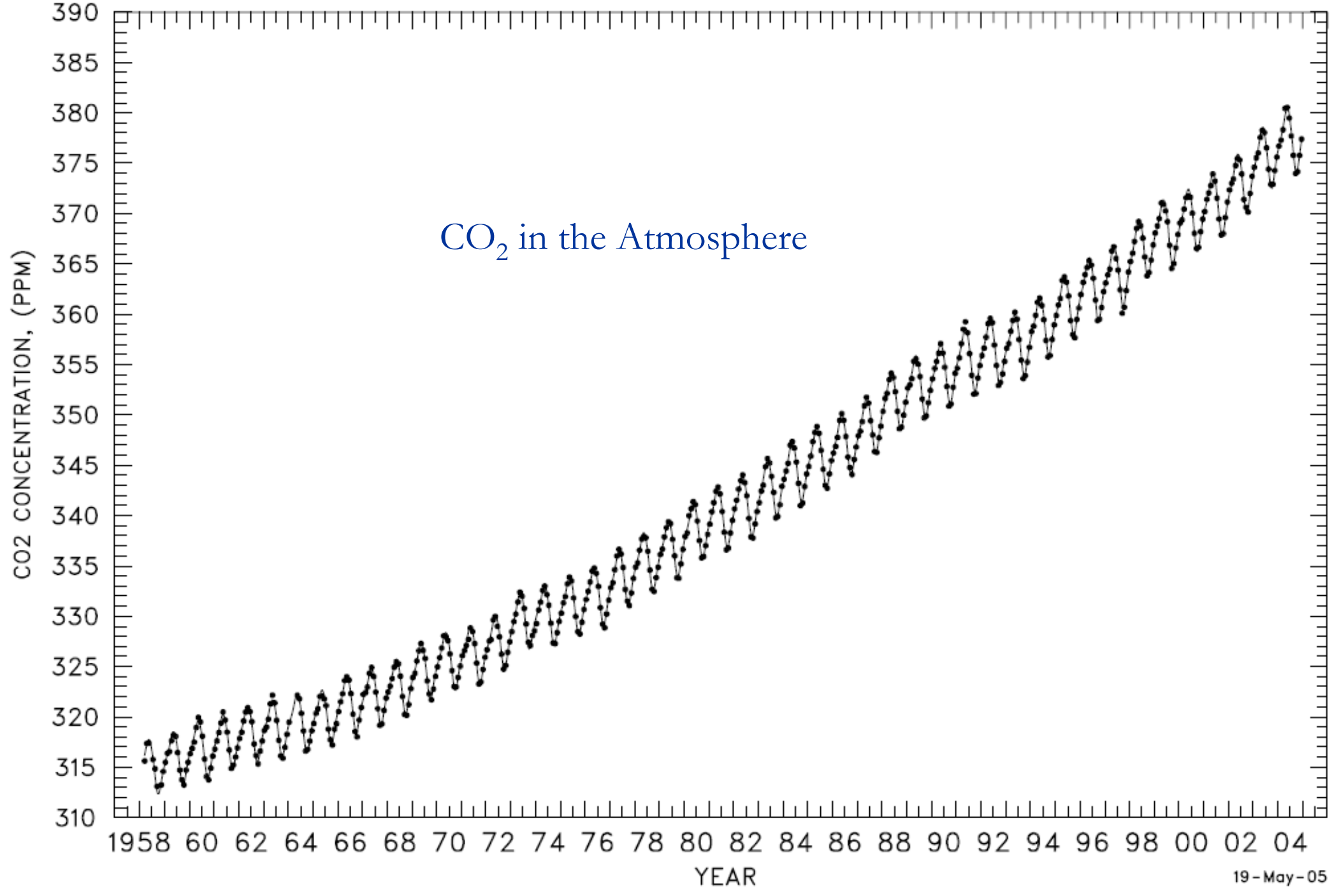



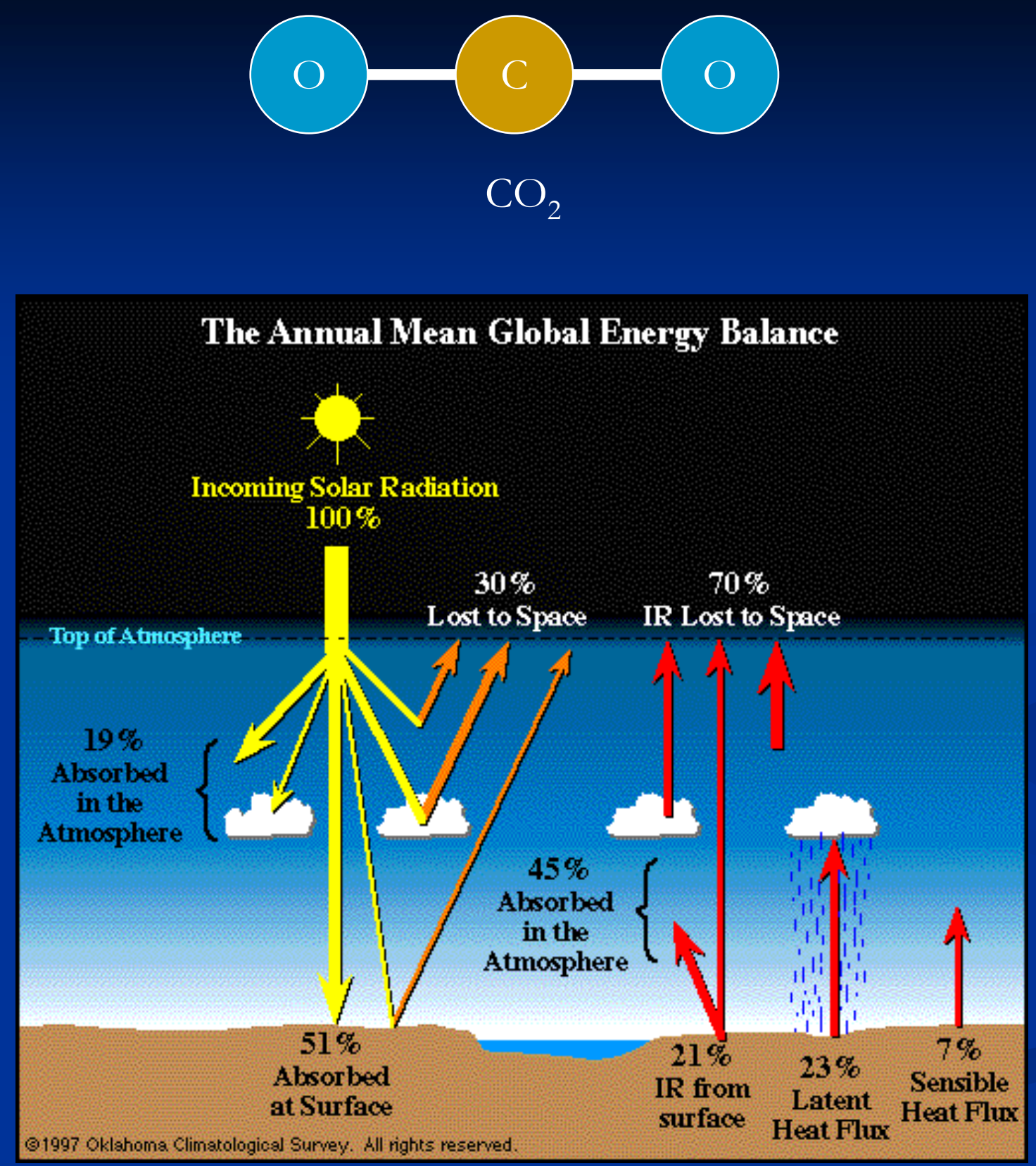


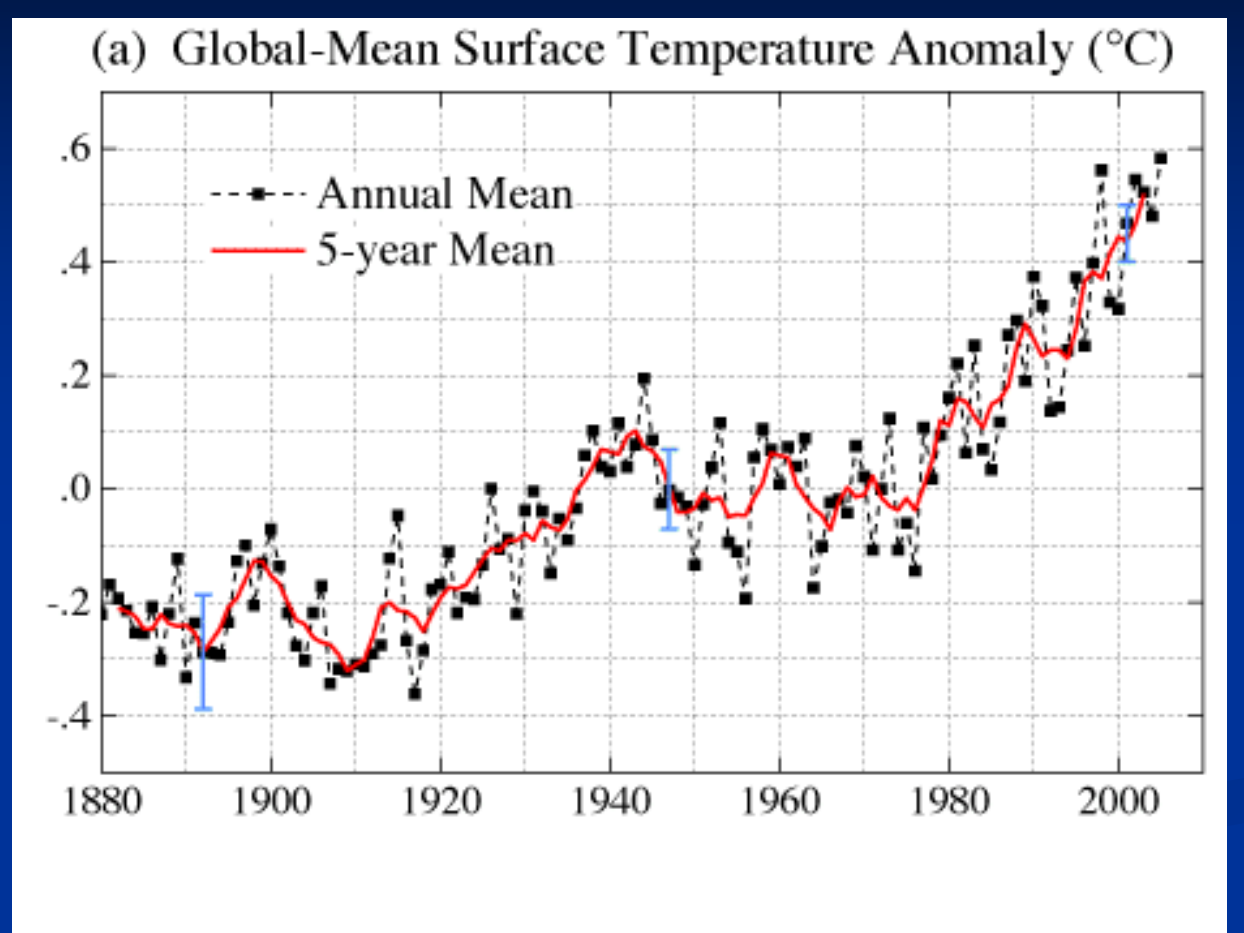

(NASA GISS) 


\section{IPCC 2007 Executive Summary:}

Most of the observed increase in global average temperatures since the mid-20th century is very likely due to the observed increase in anthropogenic greenhouse gas concentrations. 
Multi-Model Averages and Assessed Ranges for Surface Warming

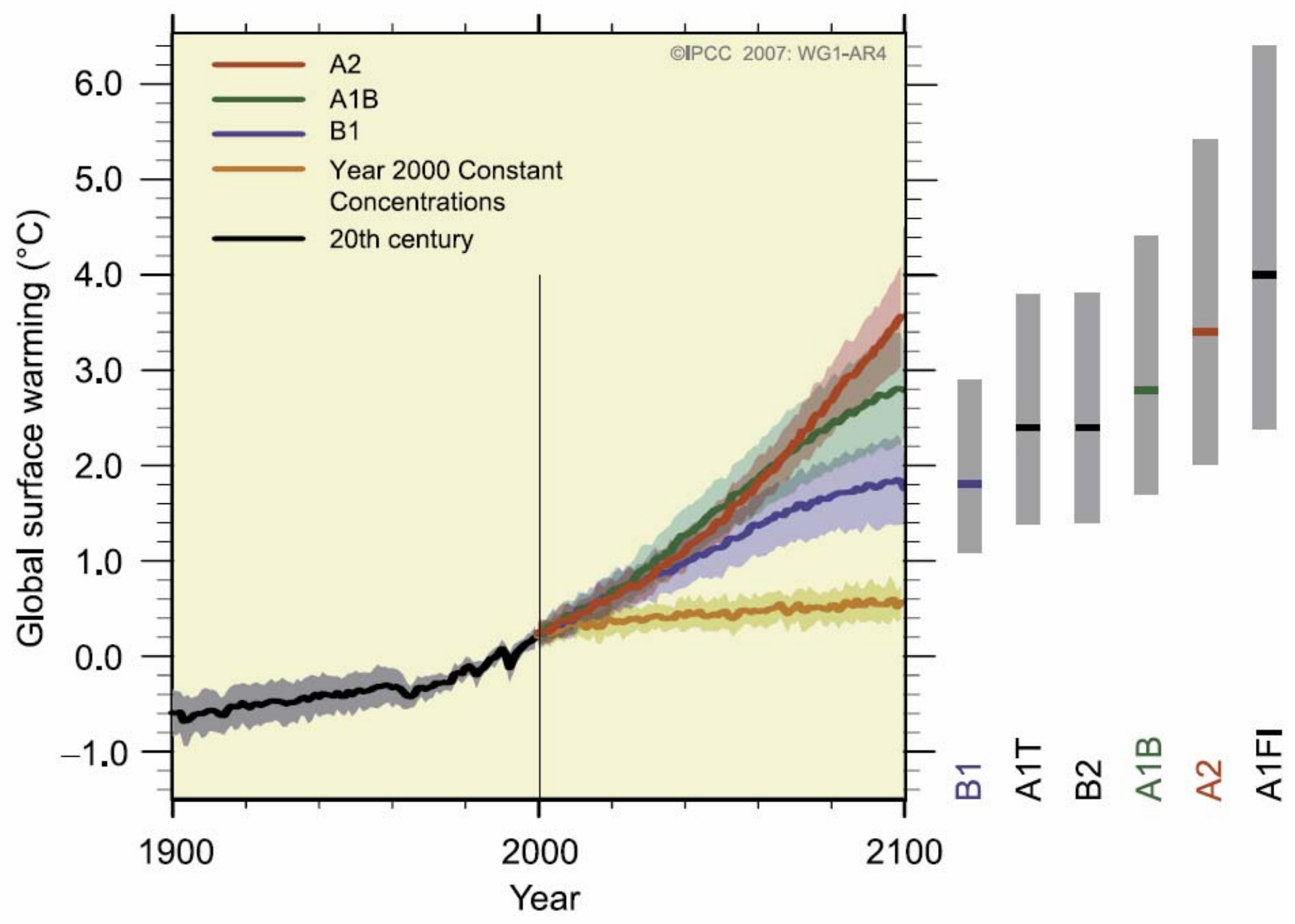

(IPCC 2007) 


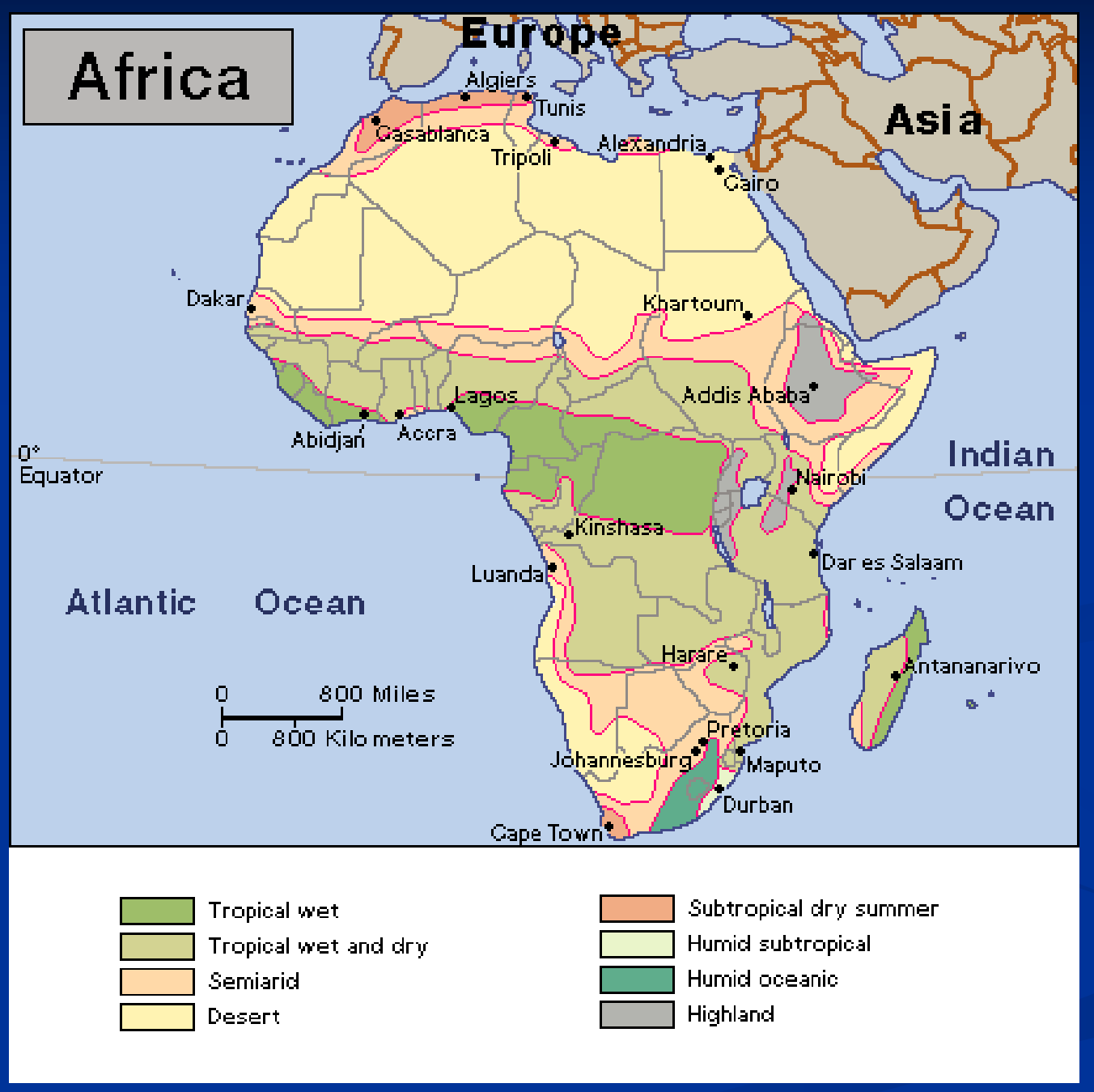


Rainfall Features 


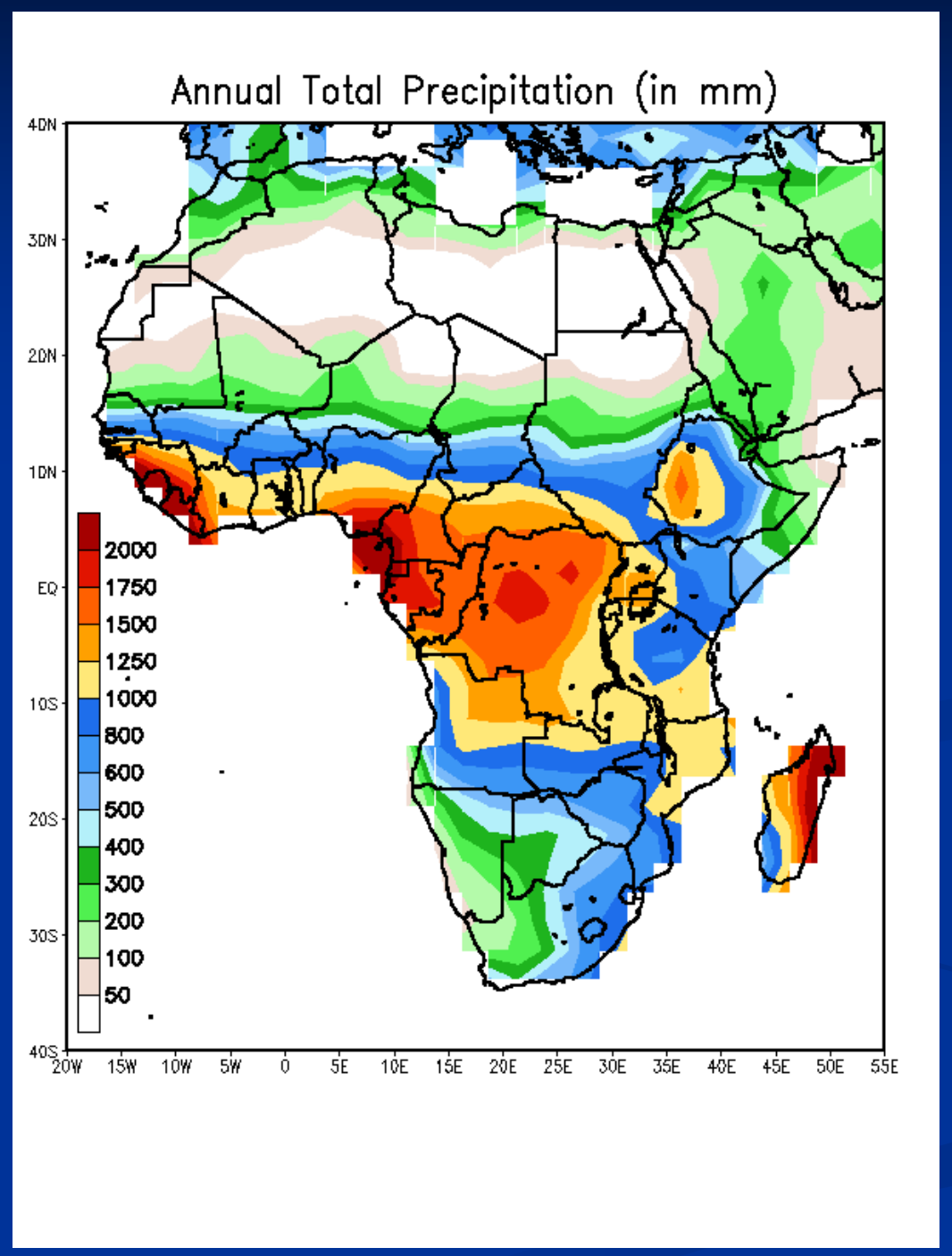




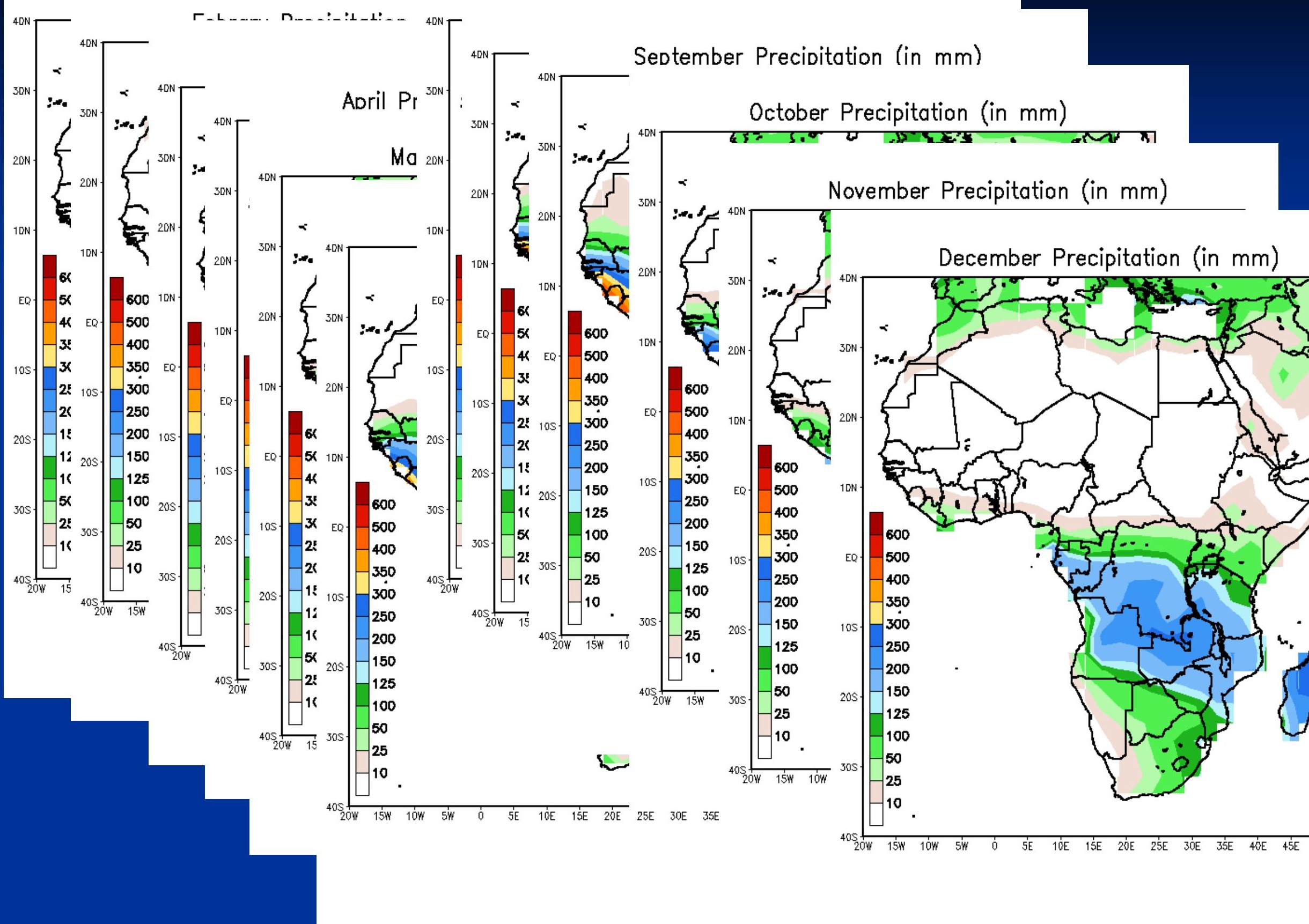




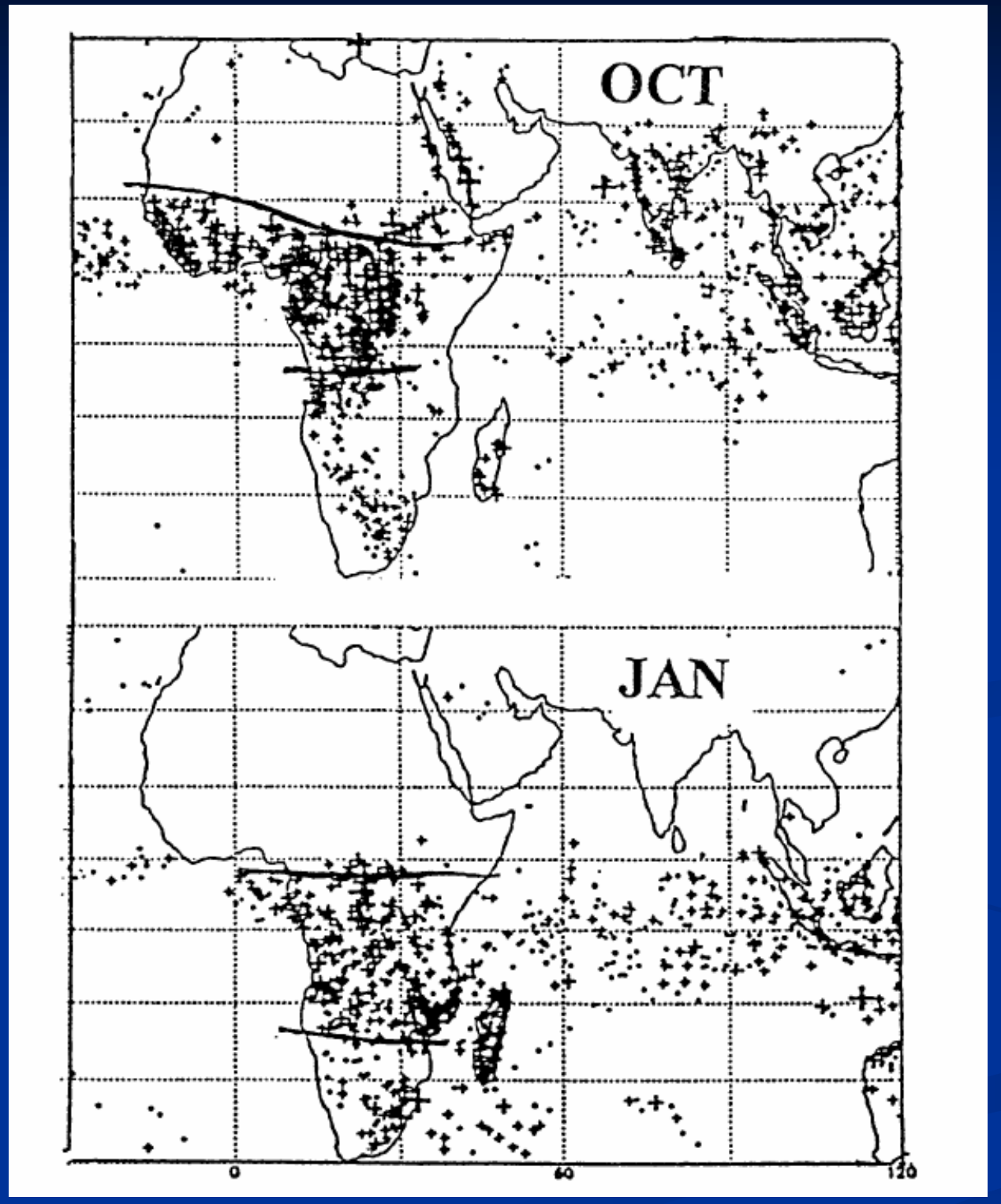

(Nicholson and Grist 2003) 
Changes in the Last Century 
Continent Average Temperature

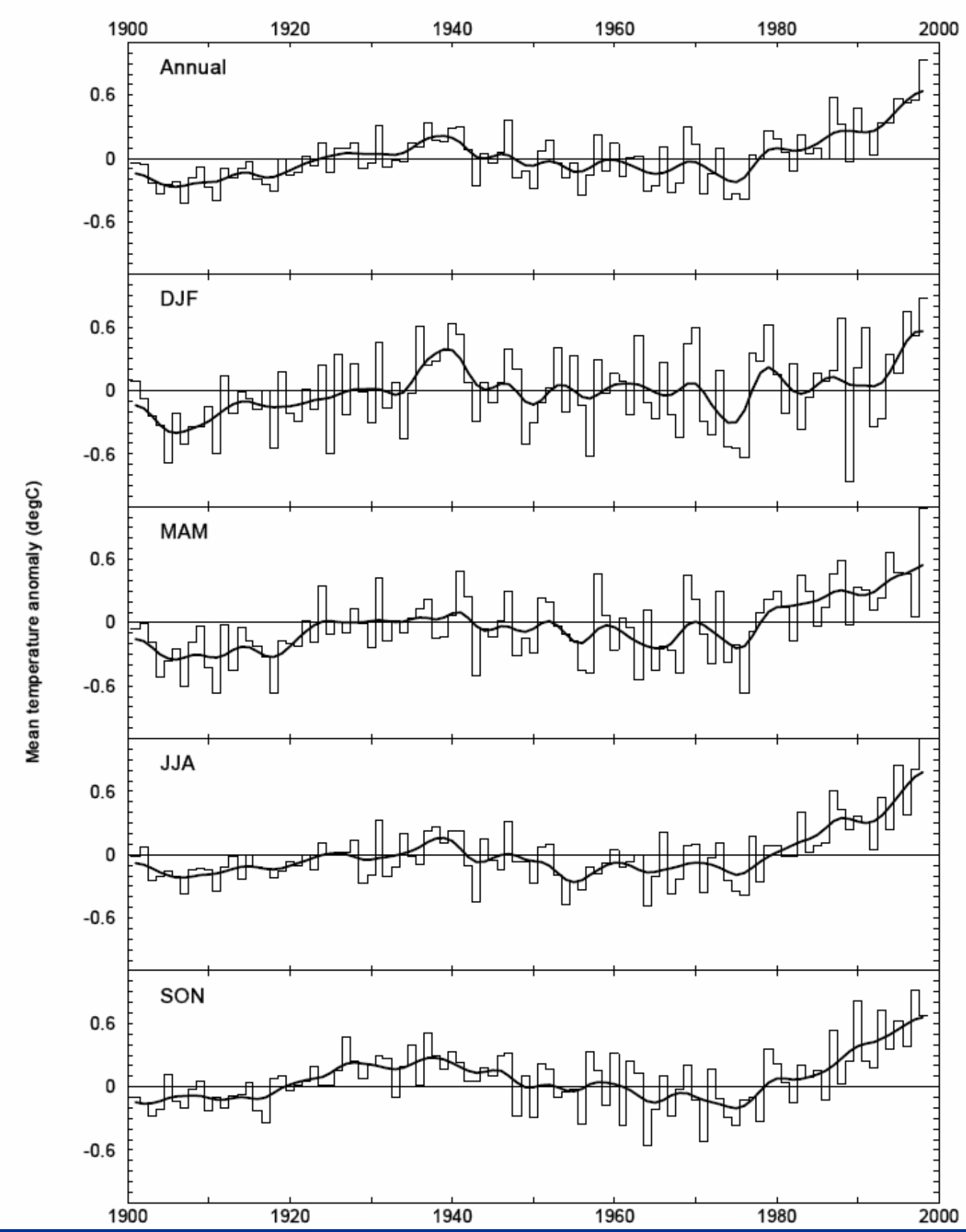

(Hulme et al. 2003) 


\section{Temperature and Precipitation Change Since 1900}

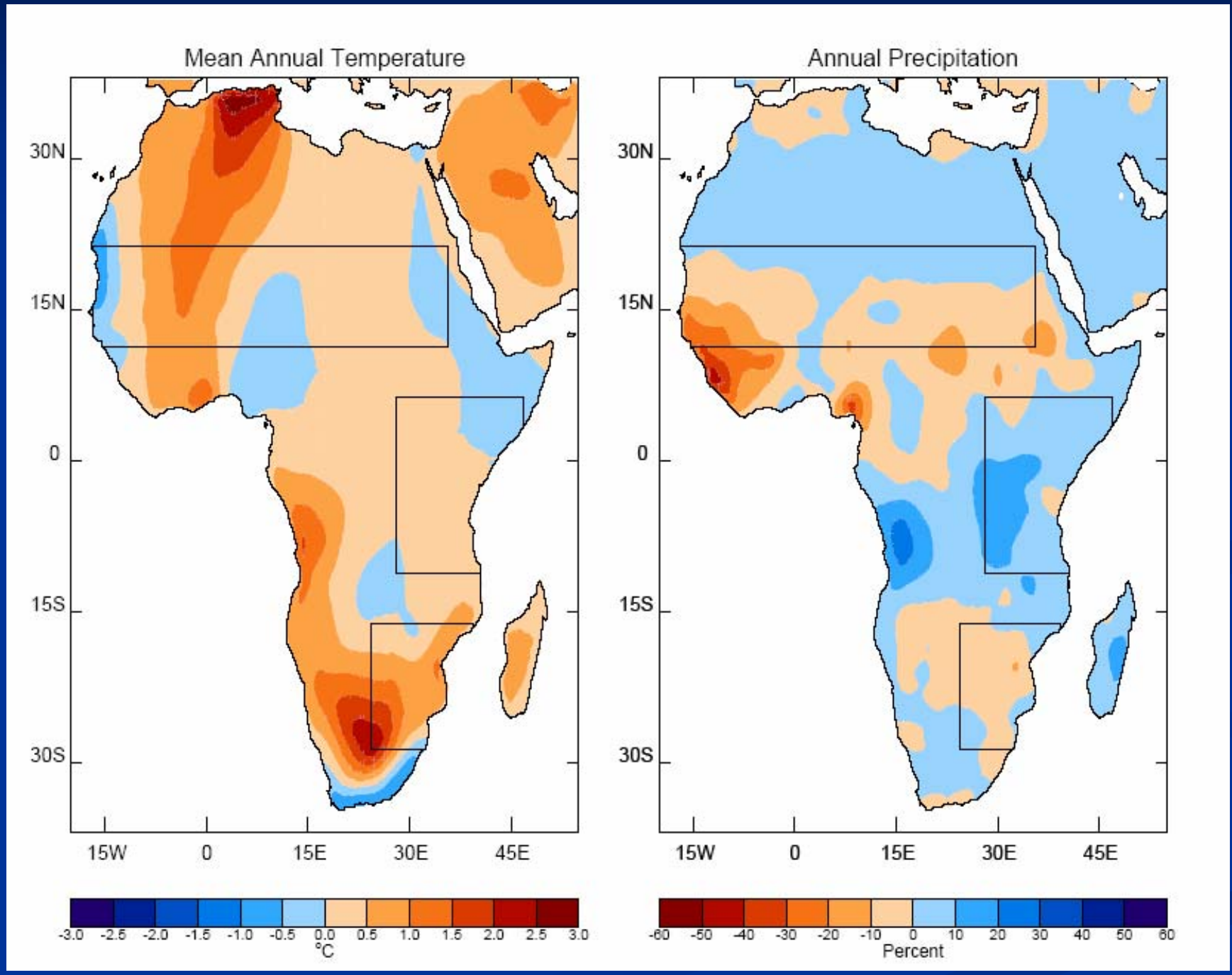

(Hulme et al. 2003) 
Temperature Precipitation Change Since 1900

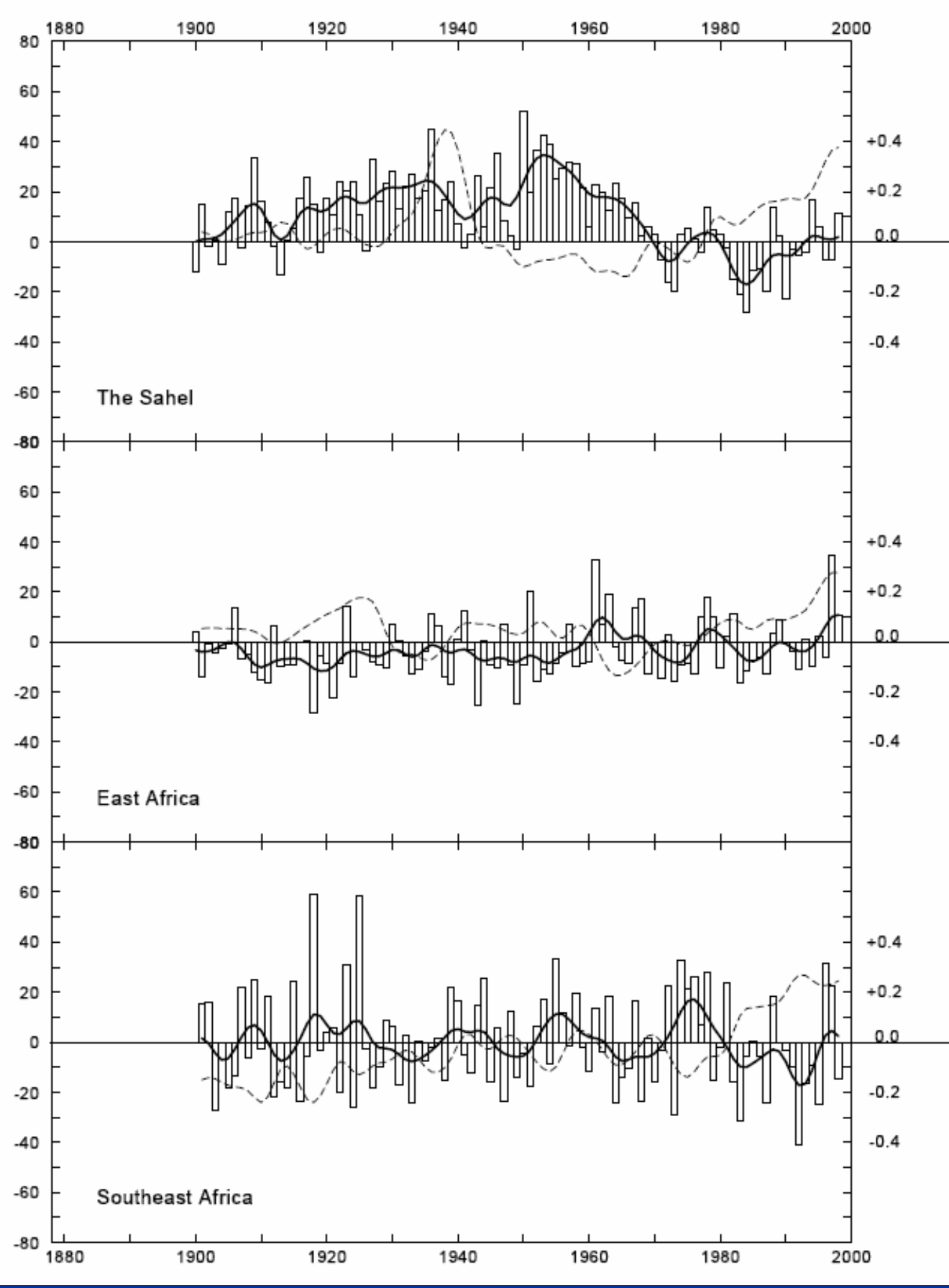

(Hulme et al. 2003) 


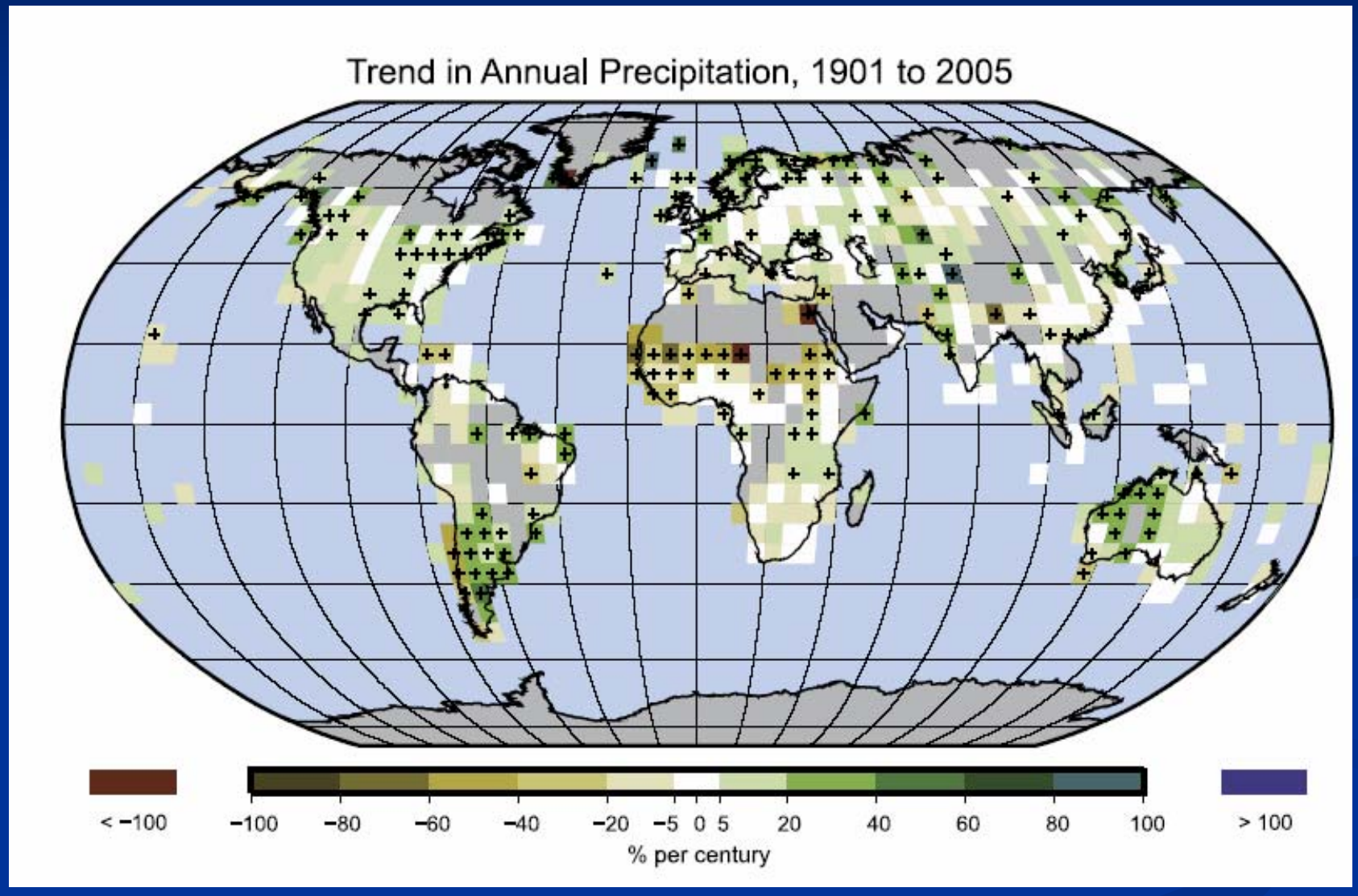


Projection for the Future 


\section{Projected Temperature Change}

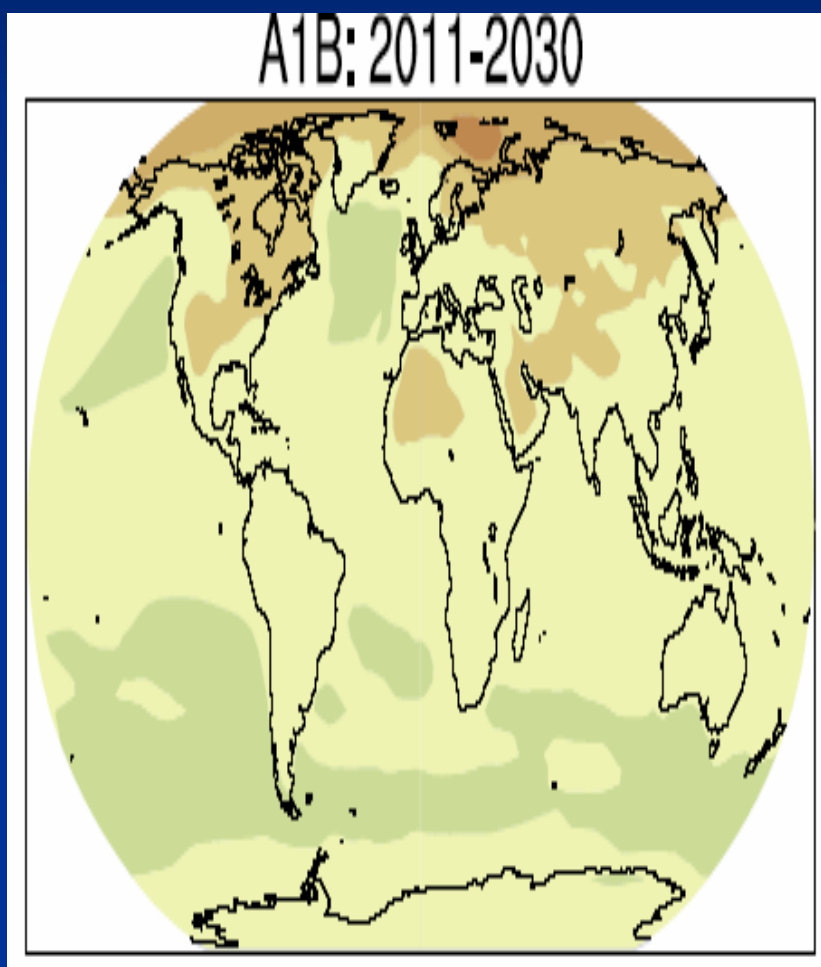

\section{A1B: 2046-2065}

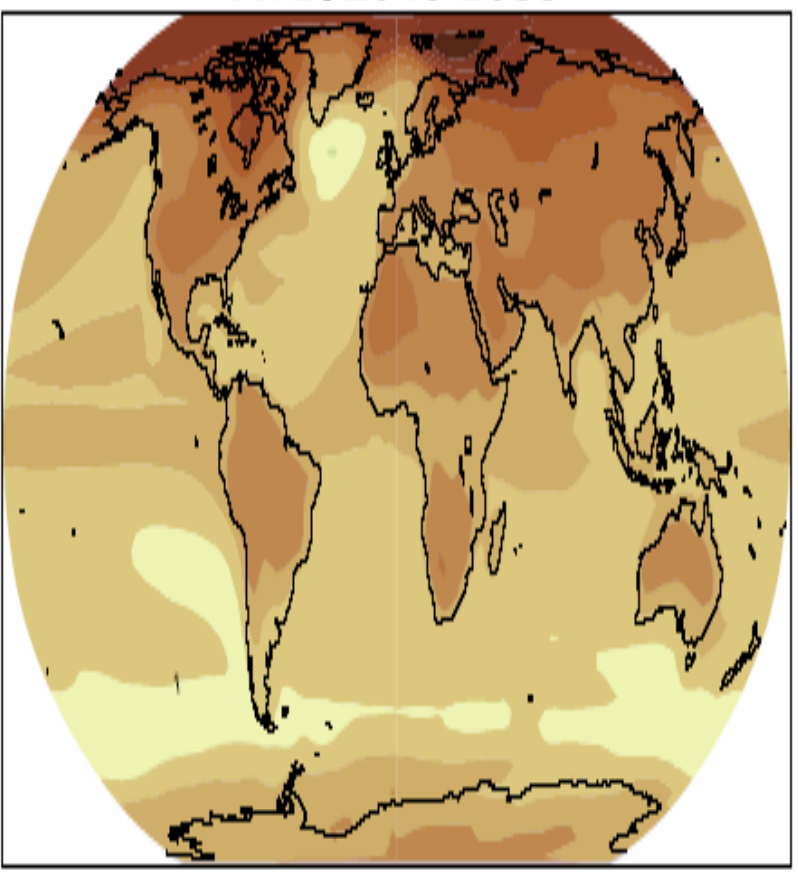

A1B:2080-2099

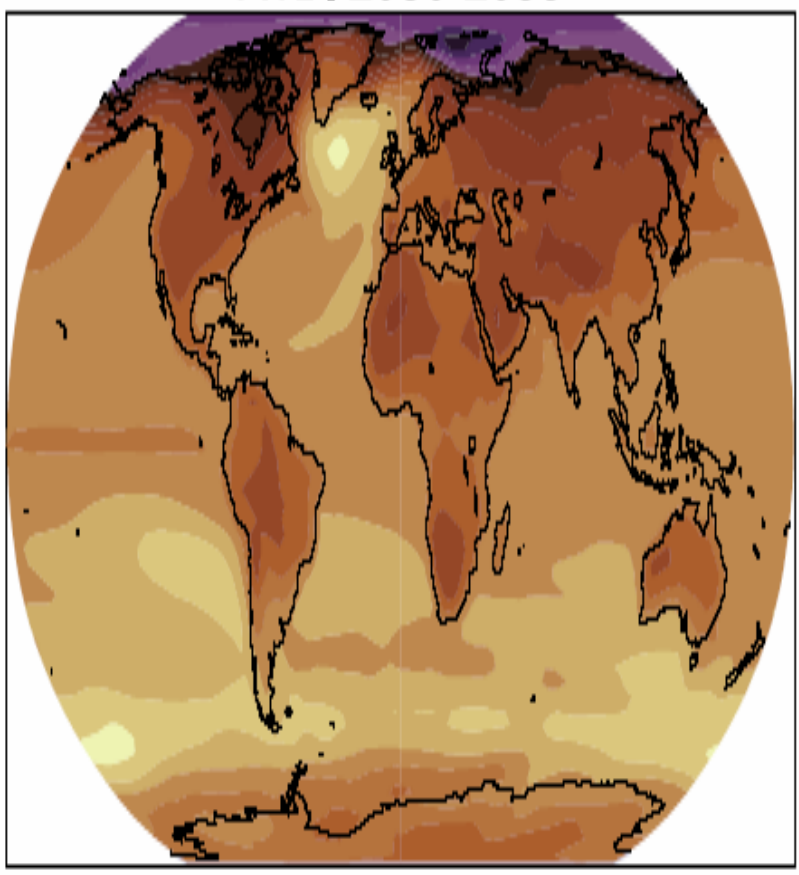

$\begin{array}{llllllllllllllll}0 & 0.5 & 1 & 1.5 & 2 & 2.5 & 3 & 3.5 & 4 & 4.5 & 5 & 5.5 & 6 & 6.5 & 7 & 7.5\end{array}$ 


\section{Projected Precipitation Change for Years 2080-2099}

\section{a) Precipitation}
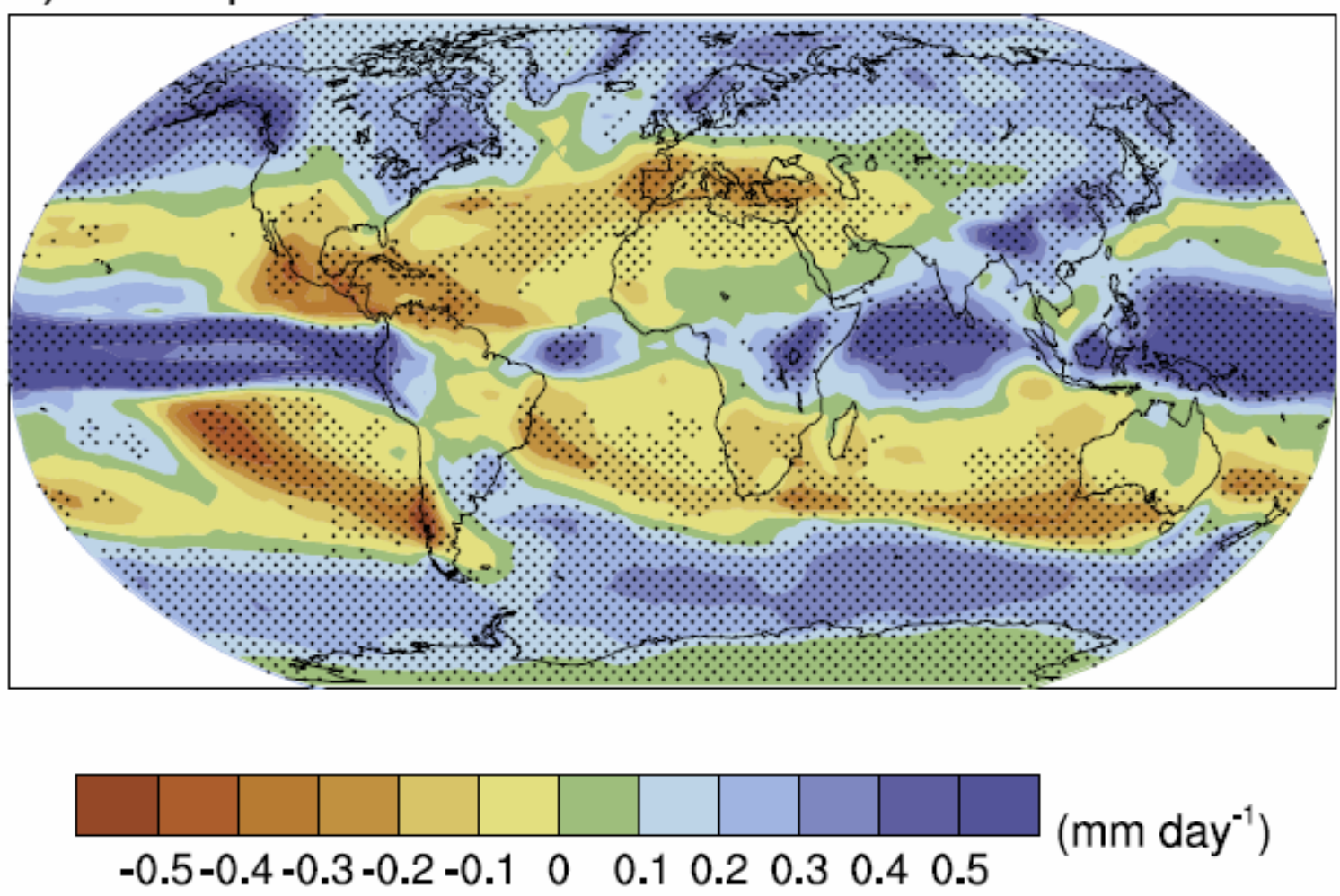

(IPCC 2007) 


\section{Seasonal Dependence of Rainfall Change}


Projected Precipitation Change

(DJF)

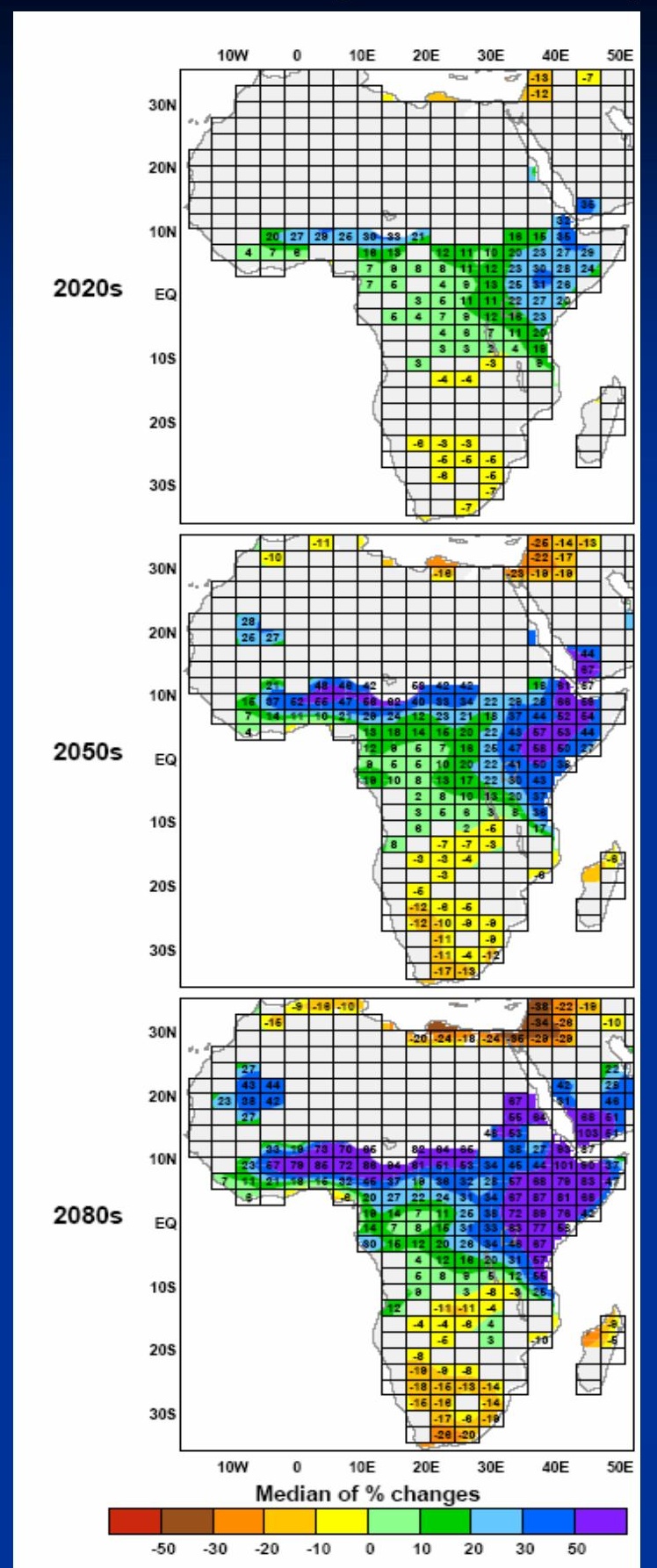

(JJA)

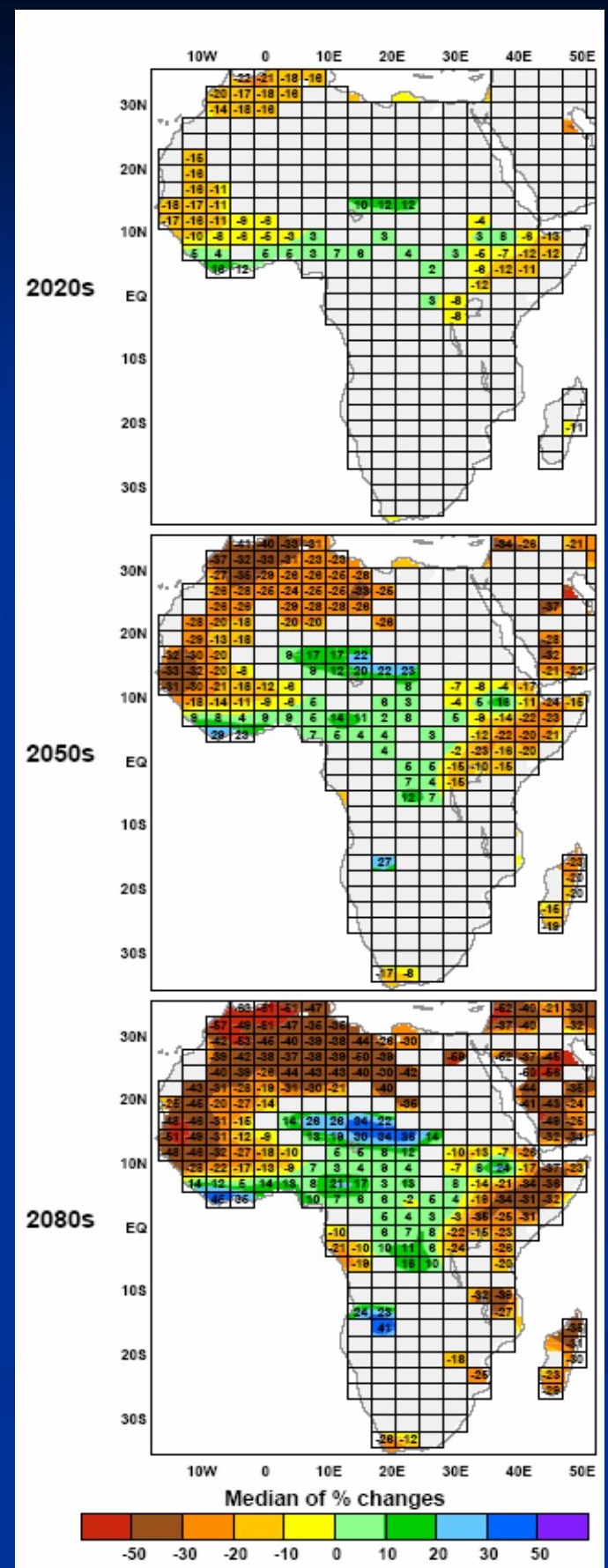

(Hulme et al. 2007) 


\section{Projected Temperature Change for Years 2080-2099}

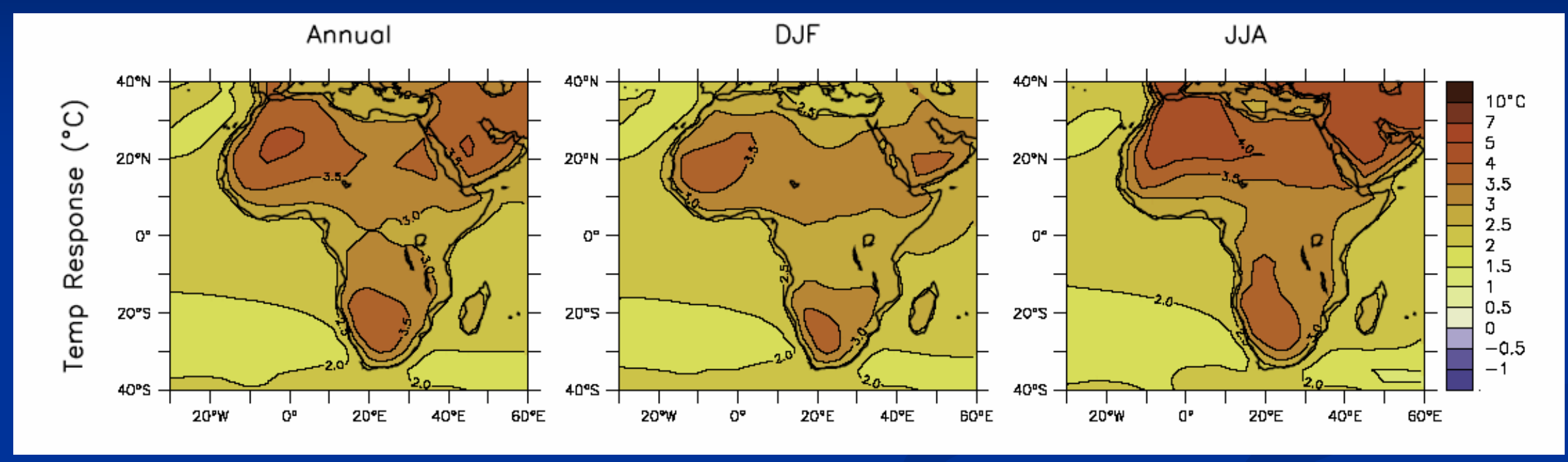

(IPCC 2007) 


\section{The Message}

1. Past Changes

Dominated by interannual and decadal variations

2. Future Changes:

Wet season wetter

Dry season drier

Warmer all seasons 